\title{
Fragility function for assessing seismic risk of typical concrete bridge by means of nonlinear static and dynamic analysis
}

\author{
Senot Sangadji ${ }^{1, *}$, Niam A. Wibowo ${ }^{1}$, Enjels N. Tropormera ${ }^{1}$, Edy Purwanto $^{1}$, \\ S. A. Kristiawan ${ }^{1}$ \\ ${ }^{1}$ SMARTQuake, Department of Civil Engineering, Faculty of Engineering, Universitas Sebelas \\ Maret, Sura karta 57126, Indonesia
}

\begin{abstract}
Bridge with concrete pier and deck is a conventional highway infrastructure built and utilized in Indonesia. More than half of these typical bridges have been in service more than 20 years. Evaluating these sort of bridge subject to various intensity of earthquake in its future service life is important. This assessment helps owner to predict damages and economic losses due to earthquake as well as to plan and devise seismic rehabilitation intervention prior to the event. The analysis uses fragility function describing the probability of exceedance of certain damage level due to single predictive demand parameter or earthquake intensity measure, i.e. spectral acceleration on bridge structure. The concrete bridge was modelled deterministically with 3-D computational structural model. Analytical non-linear static and non-linear dynamic pushover (incremental dynamic analysis) was employed to determine the structural response. Fragility function eventually is expressed as series of log normal curves which can be used to assess the seismic risk of the bridge considered.
\end{abstract}

\section{Introduction}

Bridge is essential and vital transportation infrastructure for safe and productive mobility of people and goods. In systemic point of view, bridge is actually a complex network of various components like bridge deck, girders, bearings, bents, foundations, abutments, retaining walls, and utility systems. Many of these components are quite vulnerable as affirmed by experience from past earthquakes. Due to minimum bridge structural redundancy, damage to this system ca be catastrophic. As repair of damaged bridge may be quite protractive and rerouting traffic may be notably difficult, the disruption to road networks is fatal. Further it strongly affects the emergency response in earthquake event. In the post-earthquake period, it affects rehabilitation, rebuild and revitalization of business activities of the region affected and neighbouring areas.

* Corresponding author: s.sangadji@,ft.uns.ac.id 
In many part of the world especially in developing countries, more than half of the existing bridges were developed prior to the modern earthquake resistant state-of-the art principles and practice. Risk assessment of these bridges is of important to ensure its safety as well as to decide rehabilitation intervention prior to the earthquake event. The main purpose of this paper is to demonstrate the development and the use of the fragility function for assessing seismic risk for typical concrete highway bridge. Fragility functions illustrate the probability of exceeding a certain degree of damage given of earthquake intensity parameters (e.g., acceleration spectra) on a typical concrete road bridge structure. In this work, concrete bridge will be modelled as 3D structures. The non-linear static and dynamic analytical method will be used to obtain structural response. The fragility function will be expressed as series of fragility curves that can be used to assess the vulnerability of structures at various earthquake intensities.

\section{Fragility functions and methods of its construction}

\subsection{Fundamental concept of fragility functions}

Fragility functions is defined as a functions describing the probability of exceeding different limit states (such as damage or injury levels) given a level of ground shaking. It relates earthquake intensities with the probability of exceeding certain limit states. By means of a functions describing consequences / loss due to ground motion on the damage state, vulnerability functions can be derived from corresponding fragility functions.

Fragility functions is often expressed mathematically by a lognormal probability distribution function and graphically expressed as fragility functions [1, 2]. For infrastructure at risk, fragility functions relates two parameters in the equation; seismic intensity to the exceedance probability of certain damage level as in Eq. 1 [2];

$$
P_{f}\left(d s \geq d s_{i} \mid I M\right)=\phi\left[\frac{1}{\beta_{t o t}} \ln \left(\frac{I M}{I M_{m i}}\right)\right]
$$

where $\mathrm{P}_{\mathrm{f}}$ is the conditional probability of being or exceeding a particular damage sate, DS, for earthquake intensity measure, IM, $\phi$ is the standard cumulative function, $\mathrm{IM}_{\mathrm{mi}}$ is the median value of earthquake intensity which cause the $i^{\text {th }}$ damage state, and $\beta_{\text {tot }}$ is the dispersion representing total standard deviation. Earthquake intensity parameters, IM, mas include peak ground acceleration/velocity/displacement, spectral acceleration, spectral velocity or spectral displacement. In this paper spectral acceleration, $\mathrm{S}_{\mathrm{a}}$ is chosen to be the earthquake intensity parameters as easy means to relates with damage level, as expressed in Eq. 2 [3];

$$
P\left(d s \mid S_{a}\right)=\phi\left(\frac{1}{\beta_{d s}}\right) \ln \left(\frac{S_{a}}{\overline{S_{a}}, d s}\right)
$$

with $\beta_{\mathrm{ds}}$ is standard deviation for total uncertainty of each damage condition, $\overline{\mathrm{S}_{\mathrm{a}}}$, ds is the spectral acceleration median value when the structure is damaged. The standard deviation 
value for total uncertainty of any damage condition is determined according to HAZUSMH MR5[4].

Analytical method has been employed in this paper. The methods is based on the distribution of structural damage obtained from series of numerical simulation of the structure at risk studied. In obtaining structural response the structural model is subjected to seismic input. The inputs were; [a] static as represented by response spectrum and [b] dynamic as represented by site-specific-matched scaled acceleration time-history. 3D computational models were developed based on the existing bridge taking into account trade-off between accuracy of the model nonlinear behaviour and time-efficiency of the simulation. Model with concentrated inelasticity (i.e. plastic hinge) modelling was developed for non-linear static (pushover) procedure with response spectrum input. Meanwhile fibre element model with distributed plasticity was developed for bridge model with time history input.

\subsection{Nonlinear static procedures; capacity spectrum methods from pushover}

One of the most popular methods to examine structural response and assess its seismic performance is non-linear static or pushover analysis [5 - 8]. Pushover analysis is a nonlinear monotonic static analysis performed by providing a lateral static load pattern on the structure model, which is then gradually increased by a scalar multiplier until a target of lateral displacement from a reference point is reached.

The result of a pushover analysis is a capacity curve indicating the relationship of the total base shear force with the reference displacement. In the capacity spectrum method the capacity curve is transformed into a capacity spectrum combined with the demand curve in acceleration-displacement response spectrum format (ADRS) [5 - 8].

The capacity spectrum is a curve that connects spectral acceleration with spectral displacement. To obtain spectral acceleration values, the following formula, Eq.3. [6] is used:

$$
S_{a}=\frac{V_{b}}{M_{1}}
$$

with $\mathrm{S}_{\mathrm{a}}$ is spectral acceleration, $\mathrm{V}_{\mathrm{b}}$ is base shear, and $\mathrm{M}_{1}$ is effective modal mass in fundamental vibration mode. Meanwhile, to obtain the spectral displacement value, the following formula, Eq.4., is used:

$$
S_{d}=\frac{u_{N}}{T_{1} \phi_{N 1}}
$$

where $T_{1}=\frac{\sum_{j=1}^{N} m_{j} \phi_{j 1}}{\sum_{j=1}^{N} m_{j} \phi_{j 1}{ }^{2}}$, with $\mathrm{S}_{\mathrm{d}}$ is spectral displacement, $\mathrm{u}_{\mathrm{N}}$ is displacement at the reference point, $m_{j}$ is lumped mass at point $\mathrm{j}$, and $\phi_{\mathrm{j} 1}$ is element at point $\mathrm{j}$ in fundamental vibration mode. 


\subsection{Nonlinear dynamic procedures; incremental dynamic analysis (IDA)}

Incremental Dynamic Analysis (IDA) is a parametric analysis method that predicts demand and seismic capacity of the structure. In the dynamic analysis of this nonlinear time history the structural model is subjected to one or more earthquake records (accelerograms) multiplied by scale factor (scalar multiplication) for various levels of expected seismic intensity.

The scaling increment level of the quake intensity is chosen in such a way as to 'force' the structure to work across the entire range of behaviours; from the elastic phase to the plastic phase (inelastic) until it finally reaches global dynamic instability (collapses). Due to the dynamic load that works increases in intensity, this analysis can be understood as an equivalence form of static nonlinear analysis or pushover. Even when first developed, this analysis is known as dynamic pushover analysis.

Extensive explanations of IDA's philosophy and methods can be found in Vamvatsikos and Cornell [9 - 11]. They examined IDA's basic formulations and concepts on a 20-storey steel structure with a moment-canard frame system (SRPM).

The IDA input in the structural model is a set of synthetic ground motion matching with the target spectrum response for the bridge location area. The analysis results are the response distribution of the structure expressed in the set of IDA curves. This curve shows the relation of intensity measure (IM) to the structure response (Engineering Demand Parameter [EDP]) . The EDP can be selected such as inter-story drift, drift ratio or peak floor acceleration.

Increment level increments, $\lambda$, were set uniformly for all selected artificial accelerograms. Initial intensity starts from 0.2 PGA with increment 0.2 unit up to 2 times PGA. With this increment rule it is expected that the linear elastic structure of the structure can be estimated more thoroughly. Furthermore, the increment of 1 unit, carried out from the intensity of 3 PGA until the structure gives a response assuming that the structure has collapsed. In summary the increment rules are expressed as follows; $\lambda=0.2,0.4,0.6, \ldots, 1.8,2.3,4,5,6$ $\ldots \infty$.

\subsection{Damage/limit states}

The ultimate goal of seismic risk assessment methodology is to assess the performance (or the expected loss) of the infrastructure and all its systems and components when subjected to a seismic hazard. The performance levels of a structures can be defined via threshold of damage (limit states). As damage state defines damage condition of the structure as consequence of earthquake, the limit state delineates the boundary between damage levels. With some consensus on the meaning and content qualitatively, the most common classifications of damages is the following: no damage; slight/minor; moderate; extensive; complete. However, discrete damage scale is usually required for constructing fragility curves. Numerical expression of limit states, either the accumulated consequences of all damages, or the comparison of a demand with a capacity quantity, or the consequence of a mitigation action, may also be defined as performance indicators. The qualitative description of bridge columns (pier) damage level based on HAZUS [4] and the value of limit state described by Kim and Shinozuka (2004) [13] can be seen in Fig. 1. 


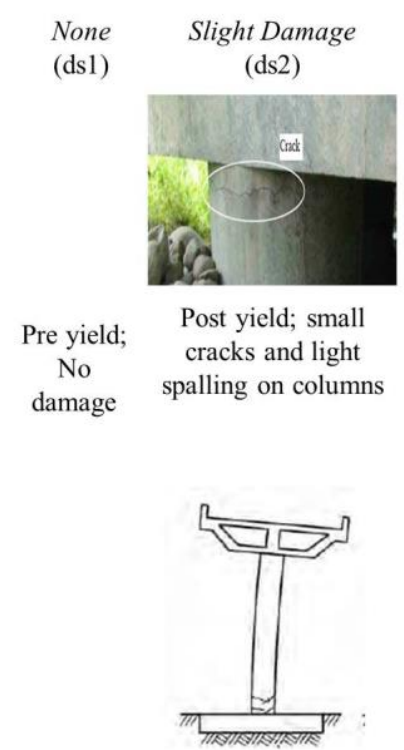

0.007
Moderate Damage

(ds3)

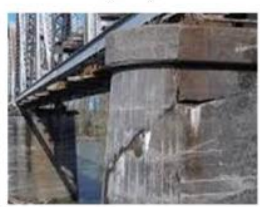

Post spalling/bar buckling; large crack/spalling but column maintains its structural capacity

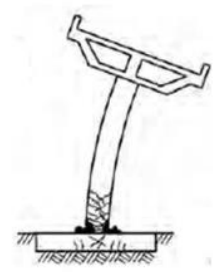

0.015
Extensive Damage (ds4)

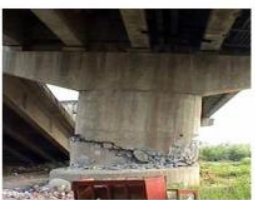

Degrading of strength; there is shear damage so the column is not safe

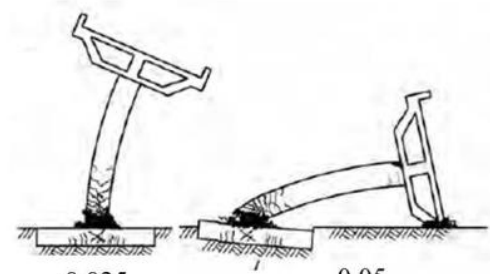

0.025
Complete Damage

(ds5)

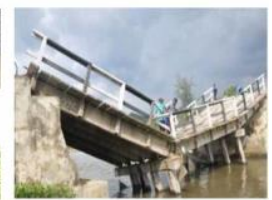

Collapse

0.05

The value of the limit state (limit state) based on Kim and Shinozuka (2004)

Fig. 1. Damage level based on HAZUS [4] and Kim and Shinozuka (2004) [13].

\section{Result and discussion; case study on existing bridge}

\subsection{Model of the structure}

The 3D computational grillage model was built based on the geometry data of Meluang-A bridge, an existing bridge located Bengkulu Province, Indonesia. It has 2 spans of $30 \mathrm{~m}$ and $30.1 \mathrm{~m}$ concrete girder supported on rectangular pier in top of hard soil as seen in the Fig. 2. The pier has cross sectional dimension of $1 \times 5 \mathrm{~m}$ with the height of $5 \mathrm{~m}$. The lead rubber bearing was modeled as elastic link boundary condition of the model which was connected to the pier head with rigid link. Longitudinal bending moment mode was observed from Eigen problem analysis with fundamental period of $0.96 \mathrm{sec}$. Fig. 2 also shows conceptually the input vectors of nonlinear static procedure as well as site-specificmatched ground motion records for nonlinear incremental dynamic analysis along with the self-weight and traffic load according to the recent Indonesian Code. Material behavior was assumed to have concentrated inelasticity therefor plastic hinge modelling was applied for push over analysis. Meanwhile distributed plasticity in the pier was modeled with fiber element when incremental dynamic analysis was employed.

Fourteen earthquake acceleration records were chosen from database, PEER ground motion database (US) and BRI strong motion database (Japan), for response history analysis. These accelerograms (time domain) were transformed into its response spectra (frequency domain). Comparison of these spectra with the target response spectra on the interval of $0.2 \mathrm{~T}$ to $1.5 \mathrm{~T}$, where $\mathrm{T}$ is fundamental period of the structure revealed the scale factor as expressed by equations [14]: 


$$
\mathrm{SF}=\frac{\sum_{\mathrm{i}=1}^{\mathrm{n}} \overline{\mathrm{A}}_{\mathrm{i}} \cdot \mathrm{A}_{\mathrm{i}}}{\sum_{\mathrm{i}=1}^{\mathrm{n}} \mathrm{A}_{\mathrm{i}} \cdot \mathrm{A}_{\mathrm{i}}}
$$

where SF is scale factor; $\overline{\mathrm{A}}$ is spectral acceleration of target response spectrum, and $\mathrm{A}$ is spectral acceleration of response spectrum of the source.

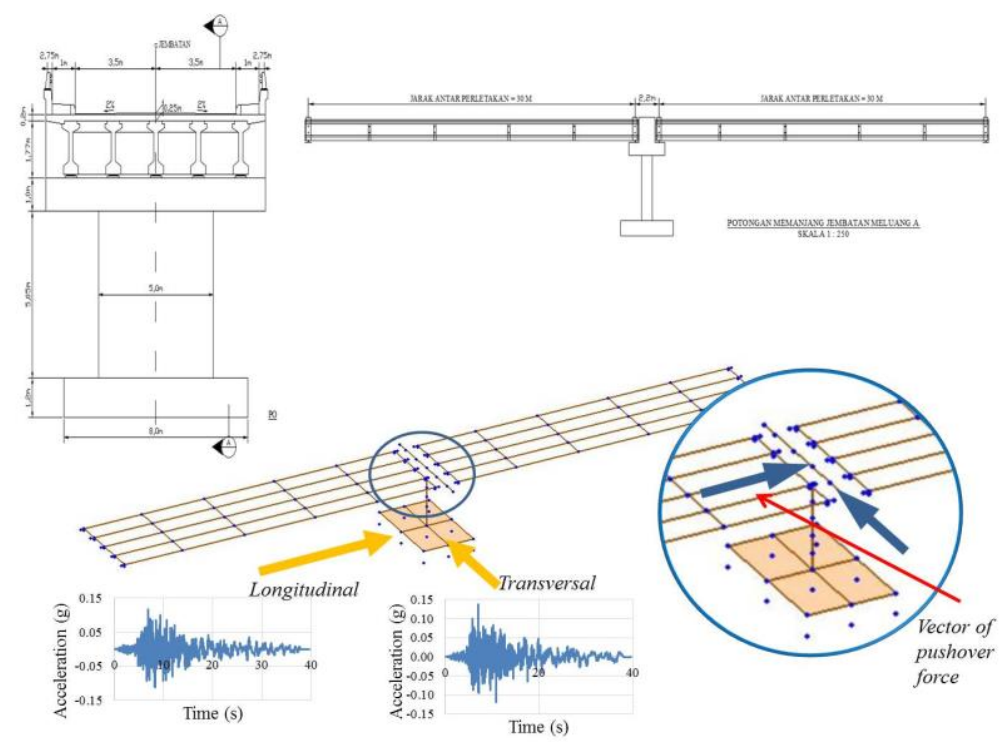

Fig. 2. The existing bridge and 3D computational model

Wavelets algorithm was then employed to spectral matching the earthquake records response spectra to the target response spectra. The matched spectrum then was converted into artificial accelerogram (acceleration time history) taking into account stochastic parameters where the results can be seen visually in the Figure 3.
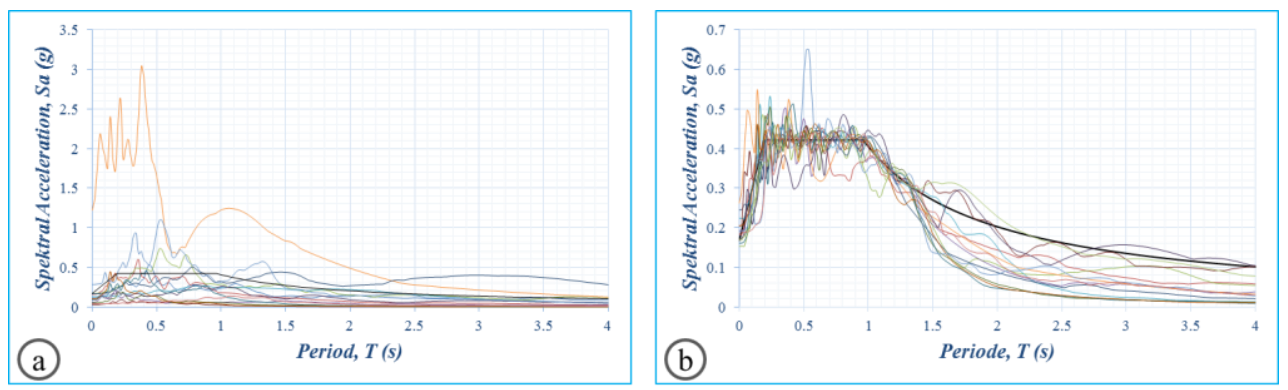

Fig. 3. (a) the unmatched earthquake spectra and (b) matched earthquake spectra with the target response spectra. 


\subsection{Fragility by means of non-linear static procedure.}

The results of the pushover analysis and the implementation of the capacity spectrum procedure are presented in the form of spectrum of capacity and spectrum demand combinations, illustrated in Figure 4. Based on the capacity curve of Meluang-A bridge, the structure undergoes a plastic yielding when the column displaced at $0.18 \mathrm{~m}$ while base shear force was $12387.2 \mathrm{kN}$ with spectral acceleration of (Sa) $1.28 \mathrm{~g}$. The spectral acceleration value is quite higher compared to the expected peak acceleration value at this bridge location namely $0.4-0.5 \mathrm{~g}$ based on the earthquake hazard map of SNI 1726: 2012. Meanwhile it is seen that the performance point is in the elastic phase of the structure. These two data lead to the assumption that the Meluang-A bridge column has a high enough capacity to withstand the lateral forces of the earthquake associated with a large enough cross-sectional dimension and a height of only $5 \mathrm{~m}$.

Based on HAZUS criteria, the spectral displacement and its associated spectral acceleration was obtained for each median value from slight to collapse damage level. For instance $\mathrm{S}_{\mathrm{d} \text {,slight }}$ was assumed at first yield at $0.49 \mathrm{~m}$ corresponds to its spectral acceleration, $\mathrm{S}_{\mathrm{a} \text {,slight }}$, as seen in the graph Fig. 3. These median value can be seen in the graph Fig. 4.

While it is seen in Figure 4 that the performance point, the point of intersection of capacity spectrum with demand spectrum is in the elastic phase of the structure. These two data lead to the assumption that the Meluang-A bridge column has a high enough capacity to withstand the lateral forces of the earthquake associated with a large enough cross-sectional dimension and a height of only $5 \mathrm{~m}$.

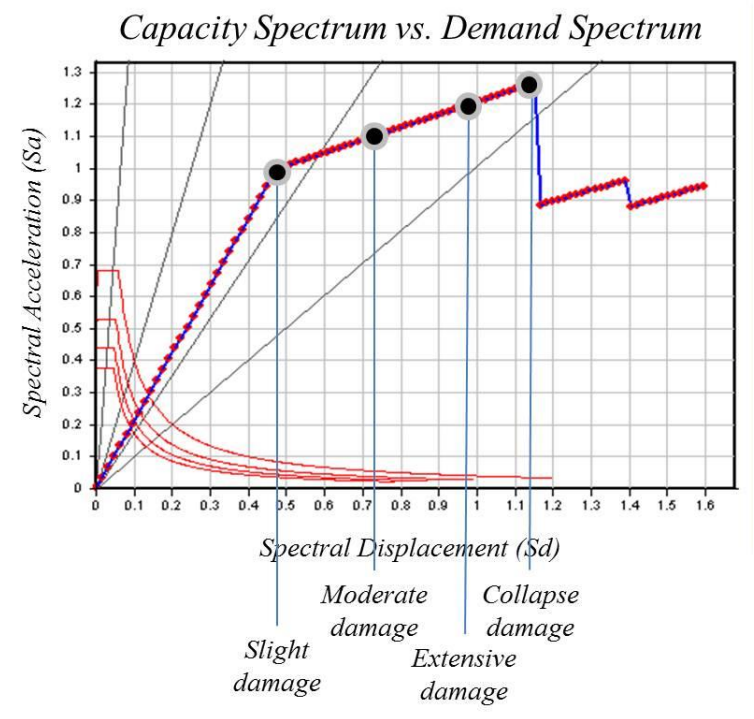

Fig. 4. The capacity spectrum of the Meluang-A bridge with damage criteria

Figure 5 exhibits the fragility curve of the bridge structure based on HAZUS-MH MR5damage criteria. The ordinate of the graph shows the probability of exceedance of 
certain damage level, from slight to collapse, as a functions of spectral acceleration. In this case fragility function is not directly related to the ground motion intensity measure but indirectly to the structural response parameters as what easily obtained from capacity curve derived from pushover analysis

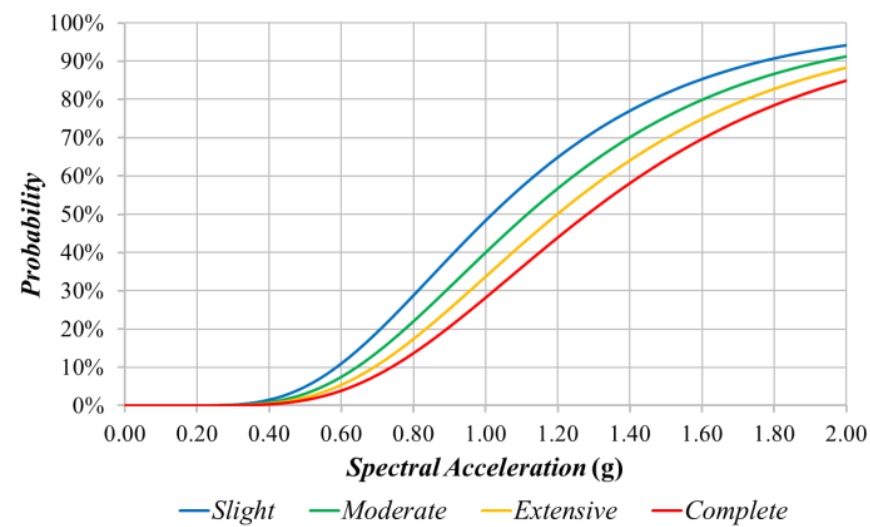

Fig. 5. Fragility curve of the structure with indirect representation by means of pushover analysis

\subsection{Fragility by means of nonlinear incremental dynamic analysis.}

Figure 6 shows the response of the structure given the applied accelerogram expressed as IDA curves. Generally, the analysis was terminated when $8 \%$ drift ratio was achieved. Linear behaviour is shown in the initial phase where all curves mostly coincide up to drift ration about $0.7 \%$. This indicates that in its initial phase the structure tends to behave linear elastic independent of the acclerogram input. Then structure exhibit nonlinear behaviour; hardening and then softening of the structure.

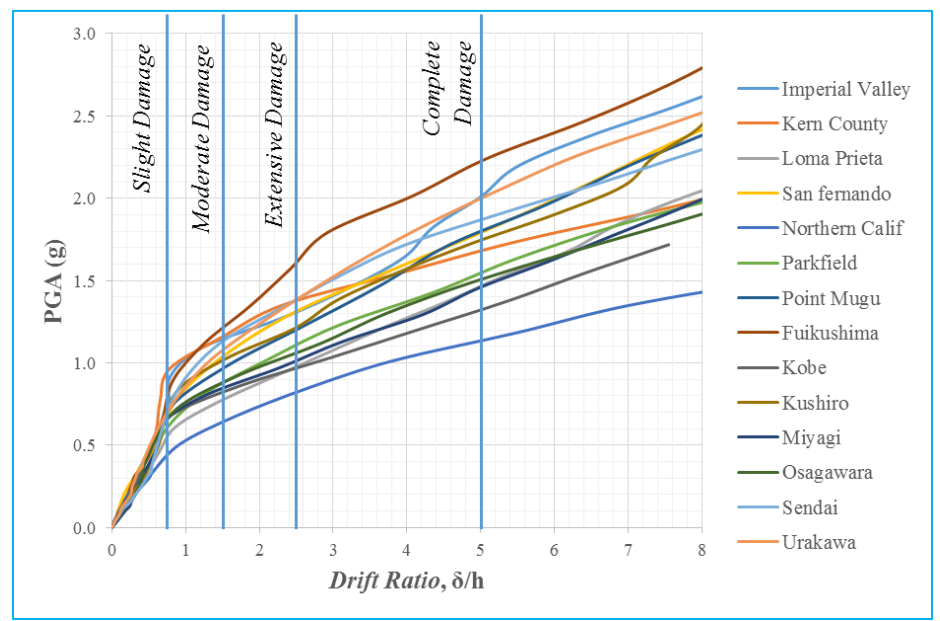

Fig 6. IDA curves from nonlinear time history analysis superposed with damage criteria 
The damage criteria was defined based on Kim dan Shinozuka (2004). Drift ratio for the bridge pier is $0.7 \%$ for slight damage, $1.5 \%$ for moderate damage, $2.5 \%$ for extensive damage and $5 \%$ for complete damage as seen in the Fig 1 . The inherent aleatory and epistemic uncertainties was treated based on the method proposed by Vamvatsikos dan Fragiadakis (2009).

With PGA obtain from from IDA curves and median capacity calculation, Fragility curves was obtained by using equation 2. The results is expressed graphically as cumulative distribution function (CDF) of log-normal distribution as seen in Fig. 7.

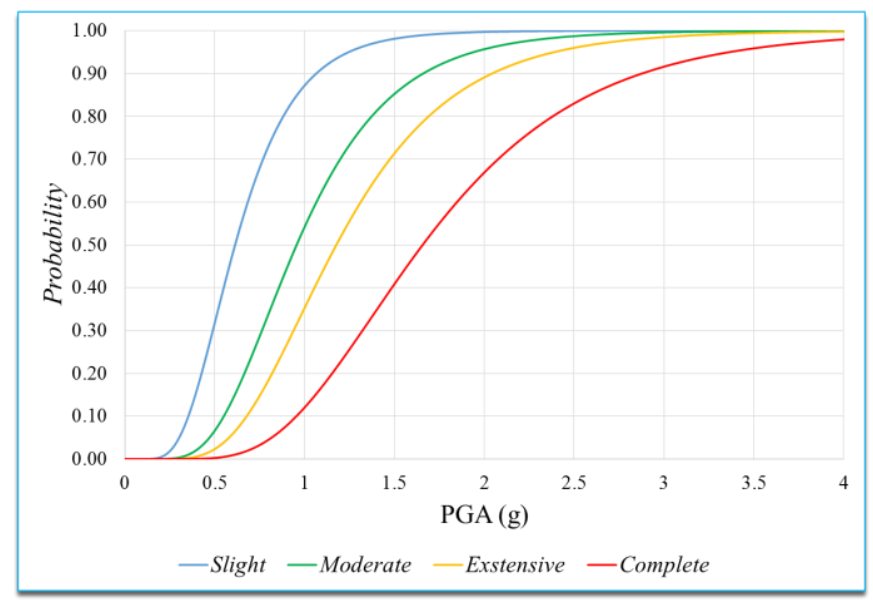

Fig 7. Fragility curve of the structure with direct representation by means of Incremental dynamic analysis

The ordinate of the graph shows the value from 0 to 1 which means zero to hundred percent certainty that some level of damage will be exceeded. The fragility curves is directly related to the expected peak ground acceleration during structures' service life.

With these curves, the evaluation of probability that the bridge structure will be damaged due to variation of earthquake intensity can be done quantitatively and rationally. For example, if the site where the bridge is located experiences earthquake with PGA about 0.4 $\mathrm{g}$ there will a chance of $2 \%$ the structure experience slight damage. From another perspective, if the $50 \%$ probability level is taken by drawing a horizontal line cutting off the fragility curve representing slight damage, then vertical line from the intersection to the PGA show the value of 0.7 . This means there is a $50 \%$ certainty that the bridge will suffer slight damage as defined by Kim and Shinozuka (2016) in the event of earthquake with PGA $0.7 \mathrm{~g}$.

\section{Conclusion}

The fragility curve of an existing bridge has been developed using a fragility function equation. The nonlinear response structure is well predicted using a nonlinear static analysis procedure. This procedure is capable of generating a capacity curve transformed into a capacity spectrum. Using the capacity curve spectral acceleration values can be obtained for 
each damage states according to HAZUS criteria. The indirect representation of fragility curve is then constructed in the form of a cumulative distribution curve as function of structural response parameter. Incremental dynamic analysis predicts the nonlinear response of the structure resulting on the direct representation of the fragility curve as a function of PGA.

\section{References}

1. Pitilakis, K., Crowley, Helen, Kaynia, Amir (Eds.). (2014). SYNER-G: Typology Definition and Fragility Functions for Physical Elements at Seismic Risk, Springer, The Netherlands.

2. Kaynia, Amir M., (ed)., (2013) Guidelines for deriving seismic fragility functions of elements at risk: Buildings, lifelines, transportation networks and critical facilities, SYNER-G Reference Report 4, European Commission, Joint Research Centre.

3. Papailia, A. (2011). Seismic Fragility Curves for Reinforced Concrete Buildings. MSc Dissertation, University of Patras.

4. Federal Emergency Management Agency (FEMA). (2010). HAZUS-MH MR5, technical and user's manual, Washington, DC.

5. Duan, X. (2008). A Procedure For Establishing Fragility Functions For Seismic Loss Estimate of Existing Buildings Based On Nonlinear Pushover Analysis. The 14th World Conference On Earthquake Engineering. China.

6. Chopra, Anil K. and Goel, Rakesh K., (1999) Capacity-Demand-Diagram Methods for Estimating Seismic Deformation of Inelastic Structures: SDF Systems., Report No. PEER-1999/02., Pacific Earthquake Engineering Research Center, University of California, Berkeley.

7. Fajfar, Peter., (1999). Capacity Spectrum Method based on Inelastic Demand Spectra. Earthquake Engineering and Structural Dynamic 28, 979 - 993. Wiley.

8. Ger, J., dan Cheng, F.Y. (2012). Seismic Design Aids for Nonlinear Pushover Analysis of Reinforced Concrete and Steel Bridges. CRC Press,. Boca Raton,.

9. Vamvatsikos, D. dan Cornell, Allin C. (2002). Incremental Dynamic Analysis. Earthquake Engineering and Structural Dynamic 2002; 31:491-514.

10. Vamvatsikos, D. and Cornell, Allin C. (2002.) Applied Incremental Dynamic Analysis. 12th European Conference on Earthquake Engineering. London.

11. Vamvatsikos, D. and Fragiadakis, M. (2009). Incremental Dynamic Analysis for Estimating Seismic Performance Sensitivity and Uncertainty. Earthquake Engineering and Structural Dynamic 2009; 00:1-16.

12. Mander, J. B. dkk. (2006). Incremental Dynamic Analysis Applied to Seismic Risk Assessment of Bridges. University of Canterbury. Christchurch, NZ.

13. Kim, Sang-Hoon, and Shinozuka M. (2004). Development of fragility curves of bridges retrofitted by column jacketing. Probab Eng Mech 19(1-2):105-112

14. Kalkan, E. and Chopra, A.K. (2010). Practical guidelines to select and scale earthquake records for nonlinear response history analysis of structures, U.S. Geological Survey Open-File Report 2010-1068, 124 p. 